\section{Escritos \& ensaios: Norbert Elias em perspectiva}

Federico NEIBURG e Leopoldo WAIZBORT (orgs.). Escritos \& ensaios. Vol. 1: Estado, processo, opinião pública. Rio de Janeiro, Jorge Zahar, 2006. 238 páginas.

\section{Tatiana Savoia Landini}

O primeiro volume de Escritos \& ensaios, organizado e apresentado por Federico Neiburg e Leopoldo Waizbort, é uma boa mostra dos textos dispersos escritos por Norbert Elias. A produção desse autor alemão é bastante vasta e diversificada. Felizmente, seus principais livros já estão disponíveis em português, a maioria em edições brasileiras. Contudo, o vasto conjunto de artigos, publicados originalmente em revistas acadêmicas ou na forma de capítulos de livros, ainda não tinha sido traduzido para o português. Esses textos aqui reunidos propiciam uma nova oportunidade de aproximação às idéias desse consagrado sociólogo.

Como afirmam os organizadores em sua introdução, a coletânea apresenta trabalhos escritos por Elias após 1950. Essa informação não deve ser desprezada. Aquela que até hoje é considerada sua obra magna, o processo civilizador (ou Processo da civilização), foi escrita nos primeiros anos do autor na Inglaterra, onde se refugiou durante a vigência do nazismo na Alemanha, sua terra natal. Publicada em 1939, por uma editora suíça, foi naquele momento muito pouco lida e apreciada. Na década seguinte, apesar de continuar a pesquisar e escrever, nenhum outro texto foi publicado pelo autor, o que aconteceu em 1950 com "Estudos sobre a gênese da profissão naval", cuja tradução constitui o terceiro capítulo de Escritos E ensaios.

Artigos e palestras são, no meio acadêmico, uma forma mais rápida de apresentar resultados de pesquisas e também de discutir aspectos específicos de um trabalho maior ou de um livro, inclusive com o intuito de reafirmar a posição teórica ou dirimir possíveis mal-entendidos a respeito de trabalhos prévios. É justamente desse ponto de vista, o da possibilidade de que sejam dirimidas dúvidas a respeito da teoria eliasiana, que serão comentados os textos de Escritos \& ensaios, não havendo a intenção, portanto, de resumi-los ou de explorar todas as questões neles envolvidas. Em sua apresentação à coletânea, Federico Neiburg e Leopoldo Waizbort já realizam parte desse trabalho. O texto, muito bem escrito, contém importantes informações a respeito dos vínculos teóricos com sociólogos de sua época e dos principais conceitos de Elias. Os organizadores também justificam a escolha dos verbetes civilização, figuração e processos sociais, escritos para um léxico de sociologia, para constituir o primeiro capítulo do livro. Segundo eles, essas definições servem como introdução privilegiada, na medida em que amarram toda a sociologia eliasiana e revelam os posicionamentos do autor no interior do campo disciplinar. Minha visão, que ficará mais clara ao final deste texto, é oposta. Os verbetes, um dos últimos trabalhos publicados por Elias em vida, deveriam ser o último texto a ser lido para que o leitor possa tiram maior proveito da criatividade sociológica presente nos escritos. Sendo assim, minhas observações seguirão a ordem cronológica (retirada de Mennell, 1998, pp. 309-312) e não aquela em que aparecem publicados no livro.

"Estudos sobre a gênese da profissão naval" (capítulo 3 - composto por dois textos, "Drake and Doughty: o desenvolvimento de um conflito", de 1950, e "Gentlemen e Tarpaulisn", de 1977), tem como ponto forte a discussão da relação entre o individual e o social. O texto discorre sobre o conflito entre dois membros da expedição que partiu de Falmouth, em 1577, com o objetivo de alcançar regiões desconhecidas no Pacífico Sul não pertencentes ao reino da Espanha. Eram eles: Drake, um marítimo profissional, e Doughty, um militar profissional, gentleman que freqüentava as altas esferas da corte, mas não tinha posses. Ao narrar suas desavenças, que culminaram com a decapitação de Doughty por Drake, Elias mostra que o conflito entre ambos deveria ser entendido não apenas como desavença pessoal, mas também como algo representativo da luta entre estratos sociais diversos. Não eram apenas dois indivíduos em luta pelo comando, mas as posições ocupadas por eles e, em decorrência, o desenvolvimento da profissão marítima. Encontramos 
aqui, portanto, um belo exemplar da sociologia eliasiana, cuja atenção está voltada não para a ação individual, mas para as interdependências entre os indivíduos.

Outro ponto bastante negligenciado por leitores de Elias, bastante bem desenvolvido nesse texto sobre a profissão naval é, por assim dizer, o lado antropológico do autor. Ao lidar com acontecimentos passados, ele trabalha com definições êmicas, isto é, busca entender os conceitos a partir das configurações que lhes deram forma. N'O processo civilizador, esse exercício se realiza quando o conceito de civilização é problematizado, sendo relacionado ao desenvolvimento da sociedade. O mesmo é feito em relação à profissão naval e às desigualdades de poder e de status.

Esse capítulo 3 é, na minha opinião, um dos melhores textos do livro. É impressionante a forma como, a partir de uma questão aparentemente banal e sem significado sociológico, Elias consegue fazer uma análise ampla, aprofundada e que, sobretudo, não fica restrita ao caso e aos personagens a ele vinculados, mas discute $\mathrm{O}$ próprio desenvolvimento das profissões e da sociedade.

O capítulo 4 - "Habitus nacional e opinião pública" - é composto por duas palestras que versam sobre esse tema, a primeira proferida em 1959 e a segunda, em 1962. A tese defendida por Elias é de que existe, sim, o que pode ser chamado de opinião pública - no caso, sendo a Inglaterra o espaço abrangido -, configurada como uma base comum à pluralidade de opiniões. O autor sustenta que existem, é claro, diferenças na forma como os jornais abordam um determinado tema, dependendo do público a que se destinam, mas, por outro lado, também aponta a presença de uma uniformidade de interesses unindo aquele país. Essa base comum é, em sua visão, bastante forte no país, dado que o nós-ideal, ou seja, a visão que um inglês possui a respeito de si próprio e de seus compatriotas, possui bastante solidez. Esta, por sua vez, advém do constante e ininterrupto desenvolvimento do Estado e da sociedade, sem que exércitos inimigos concretizassem uma invasão; de uma urbanização extraordinariamente alta; e de uma uniformização também acentuada decorrente da não existência de uma camada social camponesa (apenas o farmer).

Ainda que discutível, é importante que esse ponto, a estabilidade da opinião pública inglesa, seja salientado, pois mostra uma característica típica da sociologia de Elias: a análise, ainda que se refira a um acontecimento singular do presente, será sempre relacionada ao desenvolvimento, ao devir. Mais do que isso, esse exame leva sempre em consideração a relação entre indivíduos ou grupos - no caso da opinião pública, esse aspecto não poderia ser diferente. O Estado inglês é um campo de forças que se mantêm em equilíbrio, onde estão contidos o círculo interno do governo e do Parlamento e os grupos de interesse organizados. A opinião pública seria um grupo de pressão não especialmente organizado, mas sempre presente, com capacidade de influenciar os rumos de um caso. Além disso, outra característica do enfoque do autor é o estudo comparativo, o que ele realiza nesse texto ao comparar dois países que conhece muito bem: Alemanha e Inglaterra.

Entretanto, a meu ver, esse não é dos escritos mais interessantes ou densos no conjunto da produção de Elias. De qualquer forma, é merecedor de leitura, na medida em que dialoga muito bem com os estudos sobre mídia e comunicação de massa. Referindo-se ao final dos anos de 1950 e início da década seguinte, Elias não titubeia em afirmar que as visões expressas pelos meios de comunicação representam também as opiniões de pessoas e grupos que formam o país, recusando assim a interpretação de que esses meios possuem o poder de "formar" a opinião pública.

Se esse trabalho não é dos mais ricos dentre os que foram traduzidos para a coletânea aqui examinada, o capítulo 6, "Sobre a sociogênese da economia e da sociologia" (escrito em 1962 e publicado em 1984), é muito instigante. O termo sociogênese, utilizado constantemente por Elias, ainda causa estranheza e dúvidas, mesmo entre alguns mais afeitos à sociologia figuracional ou processual. Ainda que o termo não seja dos mais corriqueiros, o objetivo da discussão é simples: buscar a gênese social da sociologia, ou seja, compreender suas fases iniciais. Isso não significa que sua discussão esteja restrita ao estudo dos autores auto denominados sociólogos. Muito pelo contrário, entende que um conceito não de- 
va ser entendido como algo dado, sob risco de reduzir diferentes matizes no uso dos mesmos termos, em estágios anteriores ao desenvolvimento do conceito.

Embora simples, o autor torna a discussão muito estimulante, na medida em que relaciona as modificações específicas na maneira de ver a sociedade ao processo social de configuração da própria abordagem científica que, por sua vez, é entendido como parte das mudanças em processo na estrutura social. Dito de outra forma, para o autor, o desenvolvimento da sociedade desempenhou papel importante na construção de uma forma mais científica de concebê-la. O livro Involvement and detachment (1987) - publicado no Brasil com o questionável título Envolvimento $e$ alienação (1998) - deu seguimento a essa discussão, além de outros textos esparsos ainda não traduzidos para nossa língua.

Para Elias, os primeiros sociólogos compartilhavam algumas questões. Destacava entre elas a conceituação similar das mesmas experiências como indicativas da existência de "sociedade", isto é, aquilo que não era Estado, uma região do universo dotada de certa autonomia e que tinha ou constituía uma ordem sui generis. Assim sendo, a questão comum entre eles era a de saber como a sociedade tinha se desenvolvido, seus estágios, forças motrizes e a direção que possivelmente tomaria. O que está em jogo, portanto, é o nascimento do "olhar sociológico", a percepção de que uma determinada ordem de eventos possui certa autonomia ante as ações individuais e as leis feitas pelos homens, conjunto esse que deveria ser estudado de modo científico, a partir de idéias e observações factuais.

Contudo, argumenta, ainda que autores como Comte, Spencer e Marx tenham tentado proceder cientificamente, encontraram um mesmo obstáculo: cada um deles tinha uma visão firme do destino dos homens, expressa numa concepção que representava, ao mesmo tempo, o que desejavam que a sociedade fosse, o que moralmente julgavam que ela deveria se tornar e o que profeticamente acreditavam que a sociedade realmente viria a ser.

Em suma, esse texto é um belo exemplo da sociologia do conhecimento eliasiana, sociologia que se ocupa do trajeto percorrido por um conceito a fim de compreender o desenvolvimento do pensamento e a construção do saber. Mais do que isso, é um texto que ajuda a refletir a respeito do status do desenvolvimento social nessa teoria. O processo civilizador foi tido por livro evolucionista, uma discussão valorativa a respeito das mudanças sociais, que definia a direção ideal do desenvolvimento. Sobre a sociogênese da economia e da sociologia, escrito mais de trinta anos depois, parece ser um acerto de contas com esse tipo de crítica.

Os dois textos seguintes - "Processos de formação de Estados e construção de nações" (capítulo 5), escrito entre 1970 e 1972, e "Para a fundamentação de uma teoria dos processos sociais" (capítulo 7), de 1977 - podem ser compreendidos na mesma chave: um acerto de contas. O primeiro deles recupera apresentação realizada no VII Congresso Mundial de Sociologia e, assim como o texto sobre a opinião pública, também uma palestra, não é dos de maior fôlego do autor. Aproveitando a oportunidade de participar de mesa-redonda sobre "Grandes Teorias do Desenvolvimento", Elias critica um de seus principais oponentes teóricos, Talcott Parsons - também ali presente - e, assim, reafirma sua própria posição.

Aponta o caráter estático do pensamento parsoniano e o fato de suas teorias serem excessivamente amplas, não condizendo com a realidade empírica. Em sua visão, ao olhar para as ações em detrimento dos indivíduos e para a sociedade como um sistema social integrado, Parsons perde toda a riqueza da realidade empírica, o que o impede de perceber os processos de integração e desintegração presentes no desenvolvimento do Estado-nação.

No segundo texto, essa discussão é aprofundada: constitui uma ótima síntese do que pensa o autor a respeito dos processos sociais, sendo nele examinados o surgimento das teorias da evolução social e do progresso nos séculos XVIII e XIX e seu desaparecimento no seguinte. Defendendo sua posição teórica, Elias afirma que não deveriam ter sido rejeitadas as teorias que buscavam explicar o processo de longo prazo, mas apenas os elementos etnocêntricos, metafísicos e teleológicos nelas presentes.

Se há questões a serem debatidas a respeito das teorias acerca dos processos sociais, o mesmo vale para o modo como o indivíduo é compreen- 
dido nas diversas teorias sociológicas. Aliás, na visão de Elias, ambas as questões estão interligadas. Se, em grande parte, os processos sociais são não planejados é porque sua direção é definida a partir da interdependência dos atos de vontade e dos planos de muitos seres humanos. Dessa forma, para ele, a direção dos processos sociais é resultado das configurações sociais; portanto, se o objetivo é compreendê-las, de nada vale estudar os indivíduos e suas vontades e atos isoladamente, mas deve ser considerada a própria configuração.

A respeito desse ponto, é importante sublinhar uma questão muito pouco debatida sobre a sociologia figuracional ou processual, para a qual esse texto se presta de forma exemplar: o papel dos grupos organizados no delineamento da direção dos processos sociais. De acordo com a terminologia do autor, as ações desses grupos constituem as ofensivas civilizatórias e possuem, sim, um papel importante. Ofensivas civilizatórias são ações que visam a influenciar o comportamento social e introduzir mudanças, sejam elas relacionadas à sexualidade e à educação, sejam relacionadas ao Estado. Contudo, a atenção deve concentrar-se não apenas nas decorrências dessas ofensivas, mas também em sua emergência, considerada parte do processo social. Nesse sentido, o planejamento social deve ser entendido como uma possibilidade advinda do curso de um processo não planejado - o planejamento é característico de uma fase do desenvolvimento não planejado e entrelaça-se continuamente com ele.

A importância das ações planejadas, comentada acima, é também considerada no texto "Tecnização e civilização" (capítulo 2), escrito em 1986 e publicado em 1995, no qual Elias analisa a tecnização do transporte. Já no primeiro parágrafo, o autor afirma que ambos os processos tanto a tecnização como a civilização - são não planejados e de longa duração, embora surjam do entrelaçamento, da conjunção, da cooperação $e$ do confronto de várias atividades planejadas.

Em pouco mais de duas páginas, é sintetizado o seu pensamento sobre o processo de civilização. É um texto conciso - o que não é muito de seu feitio, diga-se de passagem! - e que merece ter alguns pontos ressaltados. O processo de civilização corresponde a um percurso de aprendizagem involuntária que começou nos primórdios do gênero humano e que não tem fim, apenas sua direção pode ser definida. Não tendo fim, não há como afirmar que indivíduos ou sociedades sejam "civilizados", mas apenas é possível estabelecer meios tangíveis de comparações entre estágios diferentes de uma mesma sociedade e entre sociedades distintas. Está relacionado à auto-regulação adquirida, imperativa para a sobrevivência e sem a qual as pessoas ficariam irremediavelmente sujeitas aos altos e baixos das próprias pulsões, paixões e emoções. É, portanto, um Elias bastante freudiano - já presente em sua obra magna - o que aparece aqui.

Outra questão enfrentada pelo autor diz respeito ao sentido de falar em civilização quando o mundo parecia (e parece) cada vez mais perigoso. Na cabeça das pessoas, envolvidas que estão em sua vida e em seu cotidiano, a possibilidade do risco é automaticamente associada à asserção de que o perigo é maior do que nunca o que precisa ainda ser verificado.

O último texto a ser comentado é, na verdade, o que constitui o primeiro capítulo do livro, "Conceitos sociológicos fundamentais", escrito em 1986. Os três verbetes que constituem o capítulo civilização, figuração e processos sociais - foram escritos para um léxico de sociologia publicado na Alemanha e foram encomendados para que ele pudesse sintetizar seu pensamento e expor os conceitos fundamentais que orientam suas investigações. Ainda que não seja possível negar a qualidade desses escritos, também não há como não mencionar certo estranhamento diante deles. Elias sempre fez questão de enfatizar a importância da pesquisa empírica no delineamento das teorias e dos conceitos sociológicos. Ele costumava criticar, por exemplo, a primeira parte da obra Economia e sociedade, de Max Weber, por não constituir uma análise sociológica, mas, antes, um apanhado de conceitos que, de certa forma, não encontravam utilidade na sociologia weberiana, que considerava de ótima qualidade. A leitura desses três verbetes mostra um outro Elias, mais afeito à definição concisa do que à problematização e à análise. Não há dúvida de que sua leitura pode ajudar no entendimento do conjunto de sua obra, mas, tomados isoladamente, não têm muito valor. É um complemento e, portanto, merece ser 
lido por aqueles que já possuem contato e certa intimidade com os escritos do autor. Caso contrário, há o risco da simplificação, o que não é nada desejável e, sobretudo, não seria justo para com esse autor, cuja sensibilidade sociológica e capacidade de análise da realidade empírica são, de fato, impressionantes.

Em suma, os textos que Federico Neiburg e Leopoldo Waizbort escolheram para a montagem da coletânea, apesar de heterogêneos em sua qualidade e profundidade, são de grande interesse para aqueles que se voltam para a compreensão da obra desse autor germano-inglês, além do interesse individual relacionado aos temas abordados. Nesses textos, Elias tem a oportunidade de responder a críticas a seus livros mais conhecidos e sua leitura permite a percepção clara da missão que assumiu como sua: a retomada de questões levantadas pelos primeiros sociólogos, de compreender os processos sociais de mudança de longo prazo não circunscritos ao interior do Estados-nação, sem que, contudo, fosse descuidado o estudo de relações internas ou até entre indivíduos ou grupos singulares. Aliás, um ponto sempre surpreendente na leitura de seus textos é a articulação do que muitos tomam por dois níveis: $\mathrm{o}$ micro e o macro. $\mathrm{O}$ autor não se furta a estabelecer essa interconexão: o estudo de uma briga entre dois navegadores leva-o a equacionar questões mais amplas, da mesma forma que o estudo de processos gerais e de longo prazo lhe possibilita a compreensão do individual.

\section{BIBLIOGRAFIA}

ELIAS, Norbert. (1950), "Studies in the genesis of the naval profession". British Jounal of Sociology, 1 (4): 291-309.

(1998), Envolvimento e alienação. Rio de Janeiro, Bertrand Brasil.

(2000), The civilizing process: sociogenetic and psychogenetic investigations. Massachusetts, Blackwell.

MENNELL, Stephen. (1998), Norbert Elias: an introduction. Dublin, University College Dublin Press.

\author{
TATIANA SAVOIA LANDINI é doutora em \\ sociologia pela Universidade de São Paulo \\ (USP) e docente do curso de ciências sociais \\ da Universidade Federal de São Paulo \\ (Unifesp).
}

